\title{
ПРИМЕНЕНИЕ ПУЛЬС-ТЕРАПИИ ГЛЮКОКОРТИКОИДАМИ ПРИ АКТИВНОЙ СТАДИИ ЭНДОКРИННОЙ ОФТАЛЬМОПАТИИ В ДЕТСКОМ ВОЗРАСТЕ. КЛИНИЧЕСКИЙ СЛУЧАЙ
}

\author{
Т.Е. Иванникова, Е.В. Нагаева, О.Б. Безлепкина \\ ФГБУ «Национальный медицинский исследовательский центр эндокринологии» Минздрава \\ России, Москва
}

ВВЕДЕНИЕ: Эндокринная офтальмопатия (ЭОП) - аутоиммунное воспалительное заболевание ретробульбарной клетчатки и глазодвигательных мышц, ассоциированное с диффузным токсическим зобом (ДТЗ). ЭОП в детском возрасте встречается значительно реже, чем во взрослом. Заболеваемость ЭОП у детей составляет 0,79-6,5:100 000 детей и 1,7-3,5:100 000 населения в год. Часть исследований свидетельствует о том, что при лечении активной стадии эндокринной офтальмопатии внутривенное введение высоких доз глюкокортикоидов эффективнее и оказывает меньше побочных эффектов по сравнению с пероральным приемом.

ОПИСАНИЕ КЛИНИЧЕСКОГО СЛУЧАЯ: Пациентка 17 лет наблюдалась с диагнозом Диффузный токсический зоб (ДТЗ) с октября 2016 г (13лет бмес.). При обследовании в октябре 2016 г в гормональном профиле тиреотоксикоз (ТТГ - 0,04 мкМЕ/мл, св.Т4 - 44,94 пмоль/л), высокий титр антител к рецептору ТТГ (АТ рТТГ) - 19,97 MЕ/л, в связи с чем была инициирована тиреостатическая терапия Тиамазолом.

В дальнейшем проводилась коррекция терапии под контролем гормонального профиля. По результатам ультразвукового исследования (УЗИ) щитовидной железы в динамике с ноября 2018 г (15 лет 7 мес.) отмечалось выраженное увеличение общего объема щитовидной железы.

Впервые обследована в институте детской эндокринологии ФГБУ «НМИЦ эндокринологии» МЗ РФ в октябре 2019 г. (16 лет 6 мес.). При осмотре был выявлен выраженный экзофтальм, при проведении МСКТ орбит: КТ-картина экзофтальма, утолщения наружной прямой глазодвигательной мышцы, натяжения зрительных нервов, увеличения слезных желез. В результате офтальмологического обследования установлен диагноз: OU - Эндокринная офтальмопатия, неактивная (CAS 2/7), средней степени тяжести. Лагофтальм. OS - Помутнение роговицы. С целью предоперационной подготовки были выполнены перибульбарные инъекции Дипроспан по 0,5 мл в течение 4 нед с частотой 1 раз в 7 дней.

Повторно госпитализирована в институт детской эндокринологии ФГБУ «НМИЦ эндокринологии» МЗ РФ в ноябре 2019 г. (16лет 7мес.) с целью проведения радикального лечения ДТЗ (оперативное). По данным УзИ щитовидной железы - общий объем щитовидной железы 167,1 см³. Повторно проконсультирована офтальмологом, рекомендована перебульбарная инъекция Дипроспана за 1 день до оперативного лечения.

11.12.2019 г. (16лет 8мес.) выполнена тиреоидэктомия с интраоперационным нейромониторингом.

Через 1 мес после оперативного лечения возобновились жалобы на светобоязнь, слезотечение, покраснение век, склер, болезненность в области глазных яблок. Пациентка обследована по месту жительства: по результатам экзофтальмометрии выявлена отрицательная динамика (OS 22мм от 11.2019 г., 25.5 мм - от 03.2020; OD 23 мм от 11.2019; 28 мм - от 03.2020 г.). МРТ орбит: МР-картина симметричной двусторонней гиперплазии ретроорбитальной клетчатки с формированием симметричного экзофтальма.

В связи со сложившейся ситуацией, консультирована в ФГБУ «НМИЦ эндокринологии» МЗ РФ, эндокринологом и офтальмологом принято коллегиальное решение о целесообразности проведения пульс-терапии метилпреднизолоном в дозе 500 мг 1 раз в неделю в течение 4 нед. Рекомендации были выполнены. 


\section{СБОРНИК ТЕЗИСОВ}

XVII Российская научно-практическая конференция детских эндокринологов «Достижения науки в практику детского эндокринолога»

При проведении контрольных МРТ орбит (через 1 мес и 9 мес после окончания пульс-терапии): МР-картина липогенного экзофтальма без утолщения глазодвигательных мышц. Отмечена прогрессивная положительная динамика в виде уменьшения экзофтальма, гидратации ретробульбарной клетчатки. Нежелательные явления не наблюдались.

ЗАКЛЮчЕНИЕ: Клинический случай внутривенного введения больших доз глюкокортикоидов продемонстрировавший стабильную положительную динамику течения эндокринной офтальмопатии, отсуствие нежелательных явлений, позволяет применять данный метод при лечении активной стадии эндокринной офтальмопатии у детей.

КЛЮЧЕВЫЕ СЛОВА: тиреотоксикоз; пульс-терапия; диффузный токсический зоб; эндокринная офтальмопатия 